\title{
Changes in runoff time series in Thuringia, Germany - Mann-Kendall trend test and extreme value analysis
}

\author{
J. Danneberg \\ Chair of Geoinformatics, Geohydrology and Modelling, Friedrich-Schiller-University Jena, Germany \\ Correspondence to: J. Danneberg (johanna.danneberg@lfu.bayern.de)
}

\begin{abstract}
Qualified knowledge about the impacts of climate change on hydrology is needed for the derivation of adaptation measures in the water sector. As temperature and precipitation time series in Thuringia, Germany of the last 50 years reveal that the climate is becoming warmer and drier in summer and wetter in winter, the question of changes in runoff time series arises. In the presented study, simple robust analysis approaches to detect changes in runoff characteristics are applied. A selection of 19 anthropogenically undisturbed Thuringian catchments with daily runoff time series of up to 78 years without gaps, covering different landscapes and climatic conditions in Thuringia, is made. Indicators of mean, high, and low runoff in the hydrological year, winter and summer are derived and tested for trends, using the nonparametric Mann-Kendall trend test. To analyze the impact of significant lag-1 autocorrelation (AR) in the series, a prior removal of AR from the series before testing for trend (trendfree-pre-whitening) is performed. Results show that removal of AR has only minor influence on test results and is therefore considered as not necessary. Mean flow and high flow indicators in annual and winter time frame show increasing trends, escpecially in catchments in the higher regions of Thuringia like the Thuringian forest. In summer, all indicators show decreasing trends, especially in the drier central and northern Thuringian basin area. In order to assess changes in floods, 8 gauges, covering the 50 -year time period 1949-1999, are selected. Annual maximum flow series are derived for the hydrological year, winter and summer. After fitting of 8 theoretical distributions to the samples by the method of L-moments, 3 goodness-of-fit tests are applied. Flood quantiles for the return periods 2, 5, 10, 20, 50 and 100 years are calculated from means of well fitted distributions for all gauges. To analyze change in flood values, the relative difference of flood quantiles in 2 time periods, 1949-1979 (TP 1) and 1969-1999 (TP 2), with respect to the whole time period 1949-1999 are calculated. Results show
\end{abstract}

that flood values have increased in the later time period in annual and winter time frame and have decreased in summer.

\section{Introduction}

The impacts of changing climate variables on water regime and runoff characteristics have to be assessed in order to adapt to climate change, as formulated by the IPCC (e.g. Parry et al., 2007; Bates et al., 2008). Adaptation strategies in Germany have been published on national (German Adaptation Strategy in 2008) and regional (e.g. Bavarian Adaptation Strategy in 2009) level. Before taking the step of impact-modeling - using regional climate projections to drive hydrological models (Fowler et al., 2007; Maraun et al., 2010) - a first approach in assessing possible changes in runoff is to analyze measured runoff time series (e.g. Mudelsee et al., 2006; Kundzewicz et al., 2005).

The Federal State of Thuringia in central Germany is characterized by a range of different landscapes and climatic conditions. The agricultural lowlands in the central and northern part receive about $400 \mathrm{~mm}$ precipitation annually. With annual mean temperature of about $10^{\circ} \mathrm{C}$, the climate is much warmer and drier than in the southern midrange mountains of the mainly coniferous Thuringian forest, with about $7^{\circ} \mathrm{C}$ annual mean temperature. Reaching altitudes of almost $1000 \mathrm{~m}$ above sea level, they receive annual precipitation of $1200 \mathrm{~mm}$, in winter much of it as snow. Statistical analyses of time series of climatic variables over the last 50 years (Bernhofer et al., 2003) reveal that summer precipitation has a negative tendency in Thuringia, with the strongest negative trend of about $-30 \%$ in the lowlands. In winter, a positive trend of about $+30 \%$ can be detected in the Thuringian forest and of about $+10 \%$ in the lowlands. Regarding the winter snowfalls, trends show a strong decrease of up to $-50 \%$. The temperature rise has a magnitude of up to $+1.2^{\circ} \mathrm{C}$ within 
the last 50 years in the lowlands. Time series of precipitation extremes in Western Germany show positive and negative trends depending on region and season (Zolina et al., 2008). In Thuringia, a tendency of increased extreme precipitation events in winter in the Thuringian forest can be detected (Bartels et al., 2005; Bernhofer et al., 2005).

Trend analyses of runoff time series, focusing on different flow indicators, have been carried out in varying European and worldwide regions (e.g. Stahl et al., 2010; Kundzewicz et al., 2005; Svensson et al., 2005; Lindström and Bergström, 2004; Robson, 2002). For Germany, Petrow and Merz (2009) found that flood events in 50-year runoff time series of several macroscale catchments reveal positive trends, especially in winter. Within the cooperation project KLIWA, changes in mean flow and hydrological extreme events in southern German catchments have been assessed. Results point to increasing high flow values with regional differentiation (Prellberg, 2010; KLIWA, 2008, 2003, 2002). Moreover, project results of KLIWA have led to an adaptation in dimensioning of water engineering works in Bavaria and Baden-Württemberg (KLIWA, 2006). All these works lead to the underlying question of the presented study here: what effects of climate change can be detected in Thuringian runoff time series? A special focus lies on changes in occurrence, magnitude and seasonality of extreme hydrological events: flooding and low flow periods. In Sect. 2, the database and the methods of analyses that have been applied are presented, followed by the results in Sect. 3 and a summary in Sect. 4.

\section{Data and methods}

\subsection{Data}

All analyses of the presented study have been performed using measured daily runoff data of gauges in Thuringia. The time series have been kindly provided by the Thuringian Environment Agency (Thüringer Landesanstalt für Umwelt und Geologie, TLUG). Gauges were selected according to certain requirements: the time series had to cover at least 20 years, the catchment had to be without artificial water storages, no gaps were allowed in the time series, and different landscapes in Thuringia had to be represented. These requirements led to 19 gauges with mean time series covering different periods in the years from 1922 till 2005 and mean length of 48 years (Table 1). As Thuringia is a densely populated region, anthropogenic influence on catchment hydrology, by drinking water storages or hydraulic engineering, is frequent. Even though the chosen catchments are carefully selected, anthropogenic influence cannot be completely ruled out at some gauges, which are marked orange in Fig. 1. In these catchments, the analyses of GIS data revealed some artificial lakes upstream of the gauge. Therefore, a check of homogeneity was performed by a cross-site-comparison. This consisted of visual inspection of the time series and of calculation of Pear- son correlation coefficients between all series. A high correlation coefficient $(>0.7)$ between two sites is taken as an indicator for homogeneity. It revealed that high correlation coefficients $(>0.7)$ existed in time series of spatially close gauges. Outliers were accounted for as climate induced, as they were present in all time series of close gauges. These analyses led to the conclusion that the 19 series could be used for trend detection of climate induced changes in runoff. From the daily time series, runoff indicators for different seasons of the hydrological year were calculated, to account for different changes related to flow characteristics and meteorological variables in summer and winter. Three time frames are defined: the hydrological year (1 November-31 October), the hydrological winter (1 November-30 April), and the hydrological summer (1 May-31 October).

For trend analysis, for each time frame, three runoff indicators were derived (all in $\mathrm{m}^{3} \mathrm{~s}^{-1}$ ): for mean flow, the mean daily flow in each time frame (named MQy for annual mean flow, MQw for winter mean flow and MQs for summer mean flow); for high flow, the maximum daily flow in the hydrological year (HQy) and the mean monthly maximum daily flow in winter (MHQw) and summer (MHQs); for low flow, the smallest mean flow in 7 consecutive days per year (LQy) and the mean monthly smallest mean flow in 7 consecutive days in winter (MLQw) and summer (MLQs). In total, this led to 171 time series for analysis.

As database for the extreme value analysis, a sub selection of 8 gauges, all covering the years from 1949 to 1999 , was done. Annual maximum daily stream flow series were derived for 3 time frames: hydrological year (HQy), winter $(\mathrm{HQw})$, and summer (HQs). In a first step, the time period, covering 50 years, was analyzed in total (TP all). Then, all series were split: time period 1 (TP 1) covers the hydrological years 1949-1979, time period 2 (TP 2) covers the hydrological years 1969-1999. By calculating flood values of specified return periods in the two time periods and relating them to the results from analyzing the whole time period, relative changes are detected. The length of series of 30 years ensured applicability of extreme value analysis on the time series (DVWK, 1999). All series were tested for homogeneity by application of 8 non-parametric tests. Results showed that all series were suitable for application of extreme value statistics.

\subsection{Trend analysis}

To analyze significant changes in mean flow and runoff extremes, the non-parametric Mann-Kendall trend test was used. The rank-based test was chosen because hydrological variables might not be normally distributed (Kundzewicz and Robsen, 2004). The Null hypothesis of no trend is rejected if the test statistic is significantly different from zero (e.g. Helsel and Frans, 2006); this includes linear and nonlinear trends. In the presented study, a trend was considered to be highly significant at a level of significance of $95 \%$ and 
Table 1. Characteristics of the 19 analyzed time series, corresponding catchments and mean flow values.

\begin{tabular}{llrrr}
\hline & Unit & Mean & Min & Max \\
\hline Length of series & {$[y e a r]$} & 48 & 20 & 78 \\
Catchment size & {$\left[\mathrm{km}^{2}\right]$} & 255 & 10 & 1013 \\
Discharge per unit area & {$\left[1 \mathrm{~s}^{-1} \mathrm{~km}^{-2}\right]$} & 10.5 & 2.8 & 32 \\
Annual mean daily flow (MQy) & {$\left[\mathrm{m}^{3} \mathrm{~s}^{-1}\right]$} & 2.3 & 0.1 & 11.6 \\
Annual max. daily flow (HQy) & {$\left[\mathrm{m}^{3} \mathrm{~s}^{-1}\right]$} & 18.1 & 1.1 & 103 \\
Annual 7-day low flow (LQy) & {$\left[\mathrm{m}^{3} \mathrm{~s}^{-1}\right]$} & 0.5 & 0.01 & 2.1 \\
\hline
\end{tabular}

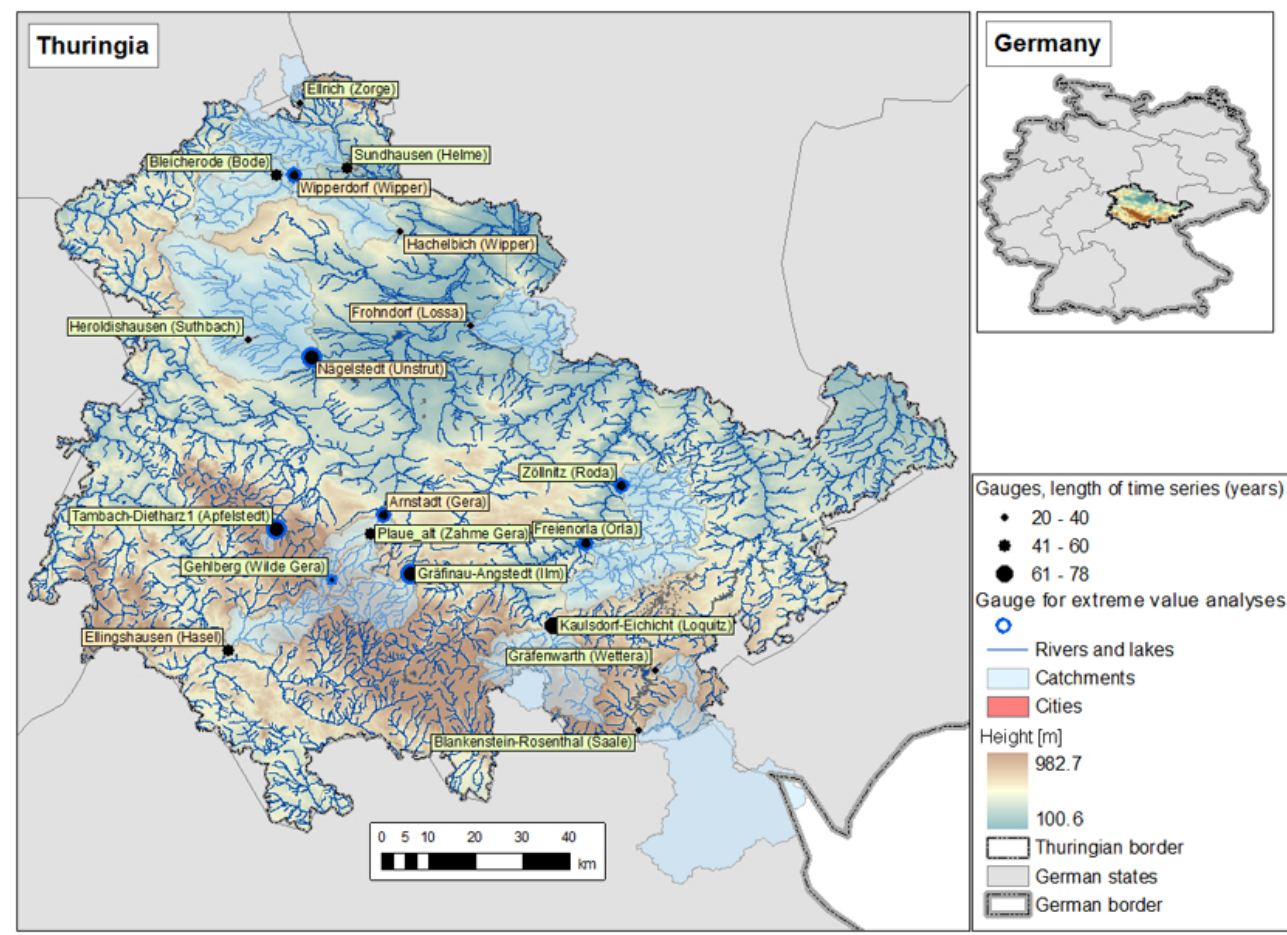

Fig. 1. Federal State Thuringia with selected gauges for trend analyses and extreme value analysis (see text for details).

significant at $80 \%$. The latter implies possibility of type $1 \mathrm{er}-$ ror of $20 \%$, therefore, focus of interpretation lies on highly significant trends. Tendencies with lower significances were considered as no trend. The test does not offer information about the magnitude of trend. An important requirement for the correct interpretation of significance levels of MannKendall test results is serial independency of the time series (Helsel and Frans, 2006). Hydrological mean and low flow time series "may frequently display statistically significant serial correlation" (Yue et al., 2002). To account for this, the procedure of trend-free-pre-whitening was applied, which consists of 5 steps and is described in detail in Yue et al. (2002) and Petrow and Merz (2009): first, linear trends are estimated for all time series, applying a robust slope estimator (after Sen, 1968, cited in Petrow and Merz, 2009). The linear trend is removed from the series in a second step by subtraction of the trend value in each time step. Next, the lag-1-autocorrelation coefficient is cal- culated in the trend-free series. If significant autocorrelation exists, this is removed from the series by subtracting the autocorrelation coefficient in each time step. In the last step, the trend is readded to the autocorrelation-free series. The resulting series shows the original trend without any lag-1autocorrelation that could possibly lead to an overestimation of trend significance. To assess the impact of autocorrelation, the Mann-Kendall test results with and without prior removal of lag-1-autocorrelation are compared.

\subsection{Extreme value analysis}

As a further measure of change in measured hydrological time series, flood return periods are analyzed as well, by using the block maximum approach. To account for uncertainty regarding the distribution of the sample, 8 possible distributions were analyzed: Pearson-2 (PE2), Log-Pearson-2 (LP2), Pearson-3 (PE3), Weibull-2 (WE2), Log-Weibull-2 (LW2), 
Gumbel (GUM), Log-Gumbel (LGU), and Generalized Extreme Value Distribution (GEV). Use of different distribution functions is recommended e.g. in DVWK (1999). Fitting of distributions to the annual series was done using the method of L-moments (LM), as this is recommended for small sample sizes (Klein-Tank et al., 2009). The performance was tested by applying 3 tests for goodness-offit, which are among the usual choice in flood quantile estimation (DVWK, 1999): Kolmogorov-Smirnow (KS), $\mathrm{n} \omega^{2}$ (NOM) and $\mathrm{X}^{2}(\mathrm{CHI})$. The Null hypothesis states that the sample is a realization of the theoretical distribution. It is rejected at a $90 \%$ level of significance, otherwise, fitting was considered "ok". Flood quantiles were derived at return periods of $2,5,10,20,50$, and 100 years. As time series in the 2 different time periods are only 30 years of lengths, the effect of possibly existing trends, which would violate the implication of identically distributed variables, is considered negligible. On the other hand, results for return periods larger than 50 years have to be considered as highly uncertain. From all distributions, the means of the calculated flood quantiles were calculated.

To account for the uncertainty of extreme value analysis from different distributions, several analyses were performed. First, flood quantiles of annual maximum flow are compared to the database of the operating institution, the Thüringer Landesanstalt für Umwelt (TLUG), which have kindly been provided for comparison. TLUG flood return values have been derived with varying methods from longer time series. To assess the uncertainty of the method resulting from selection of distributions, the standard deviations of flood quantiles from all 8 distributions with respect to mean of all distributions was calculated for all flood quantiles. In a next step, means of flood quantiles were calculated using only those distributions, for which 2 of the 3 goodness-of-fit tests did not reject the Null hypothesis. By calculating the standard deviations from the mean and comparing it to the standard deviations using all distributions, a quantification of reduced uncertainty from using only "well fitted" distributions was possible.

In a last step, the flood quantiles derived for the two time periods are compared and analyzed with respect to changes.

The procedure is a broad approach and results strictly have to be seen as a first indication of changes in extreme flood values. Constraints apply to the choice of extreme value distributions, to the parameter fitting method, and the splitting of time series as a method for change analyses. Further information regarding mathematical foundation of different extreme value distributions, maximum-likelihood method for parameter estimation in small datasets and extreme value analyses in non-stationary time series can be found e.g. in Coles (2001).

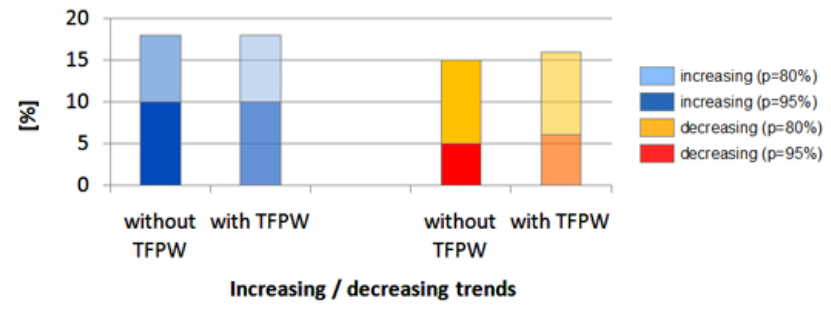

Fig. 2. Total percentage of increasing and decreasing trends in the 171 time series of all 3 runoff indicators (mean, high, low) and all 3 time frames (hydrological year, winter, summer); significant trend: $p=80 \%$; highly significant trend: $p=95 \%$; difference of trend results without prior removal of significant autocorrelation by trendfree-pre-whitening (TFPW) and with TFPW.

\section{Results}

\subsection{Trends in runoff time series}

Mann-Kendall trend tests of timeseries of 19 runoff gauges in Thuringia, covering time periods from 20 up to 79 years, reveal more increasing than decreasing trends. Considering the 3 time frames and 3 flow indicators that have been analyzed, from the total of 171 time series, $18 \%$ showed significant increase and $10 \%$ showed highly significant increase. In contrast, $15 \%$ were considered decreasing and $5 \%$ showed highly significant decrease.

As autocorrelation can influence results in terms of significance, trend analyses were also performed with prior removal of significant autocorrelation from the series by applying trend-free-pre-whitening. This revealed that $36 \%$ of the analyzed series have lag-1-autocorrelation at a level of significance of $90 \%$. Regarding flow indicators, significant autocorrelation can be detected in time series of mean and low flow, but less in high flow; regarding time frame, autocorrelation is present mostly in annual series, but also in hydrological summer and winter. Regarding the significance of the Mann-Kendall test results, prior removal of significant autocorrelation by trend-free-pre-whitening has very little effect. For decreasing trends, $1 \%$ more flow series are considered significant and highly significant respectively (Fig. 2). From the results of the trend-free-pre-whitening procedure, it was decided that possibly present autocorrelation in the series can be disregarded in this case. Therefore, the following presented results are based on the original time series.

From Fig. 3 it becomes obvious that in annual and winter time frame, all flow indicators show mostly increasing trends. In summer, all flow indicators show mostly decreasing trends. Regionally, the midrange mountains show increasing trends in annual and winter series and decreasing trends in summer series. 


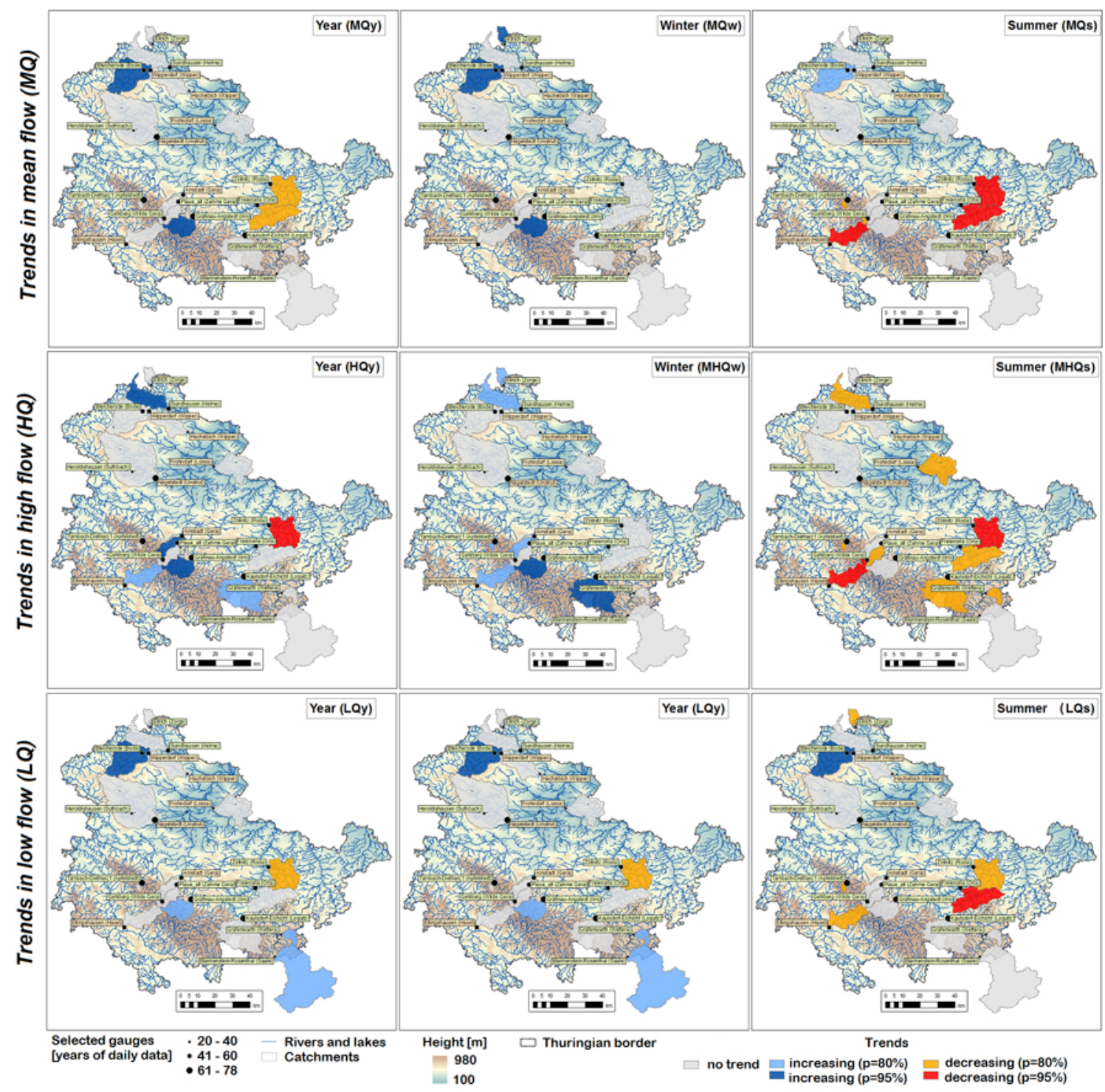

Fig. 3. Mann-Kendall trend results in mean flow, high flow and low flow time series in Thuringian catchments; increasing and decreasing trends are considered significant at a level of significance of $80 \%$ and highly significant at $95 \%$.

\subsection{Extreme value analysis of high flow}

Here, the results of analyses of annual time series of maximum daily runoff at 8 Thuringian gauges in annual, winter and summer time frame within the hydrological years 19491999 are presented.

Results imply several conclusions: in the later time period (TP 2, 1969-1999), flood values are increasing in annual series (mean for all return periods: $+6 \%$ ) and winter series $(+15 \%)$ and decreasing in summer series $(-3 \%)$, when compared to the reference values from the whole time period (Fig. 4b). This stands in opposition to the earlier time period (TP 1, 1949-1979), where flood values are smaller in annual and winter series $(-5 \%,-3 \%)$ and higher in summer series $(+8 \%)$ (Fig. 4a) . These results regard all considered return periods $(2,5,10,20,50$ and 100 years $)$ and most gauges (Fig. 4a-d).

In sum, the results indicate increasing flood values in annual and winter floods at most of the analyzed gauges in Thuringia in the years 1969-1999, when compared to the reference. For example, at gauge Arnstadt in the Thuringian forest, winter flood values show a mean increase of $+40 \%$ for all return values (Fig. 4d).

For the derivation of runoff values at different return periods, only the results of those distributions were considered, for which 2 of the 3 tests yielded "ok" fit. Some distributions show generally worse performance, than others, namely the Gumbel (GUM) and the Log-Gumbel (LGU) distributions. 


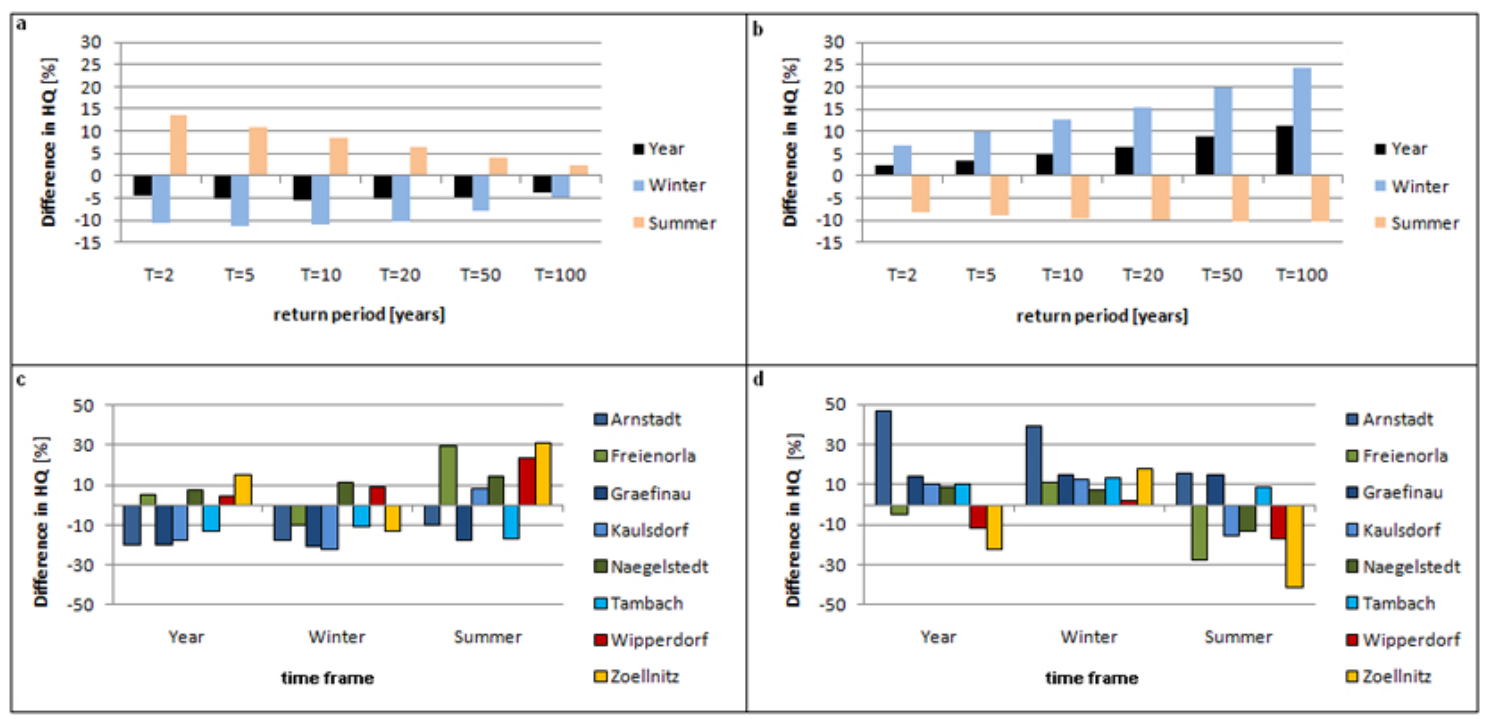

Fig. 4. (a-d) Changes in flood return values for 8 gauges in different time frames (hydrological year, winter, summer) when comparing 2 time periods (TP 1: 1949-1979; TP 2: 1969-1999) to the whole time period (TP all: 1949-1999); upper graphs: mean changes at 6 flood return periods [\%] for all gauges in different time frames; lower graphs: mean changes of all flood return values [\%] in different time frames at 8 gauges; left side: TP 1, compared to TP all; right side: TP 2, compared to TP all.

Moreover, at some gauges, the fitting procedure is generally less successful than at others and seasonal differences can be noted. It is beyond the scope of this paper to address these issues, but differences in performance of distribution fitting to runoff time series is considered a highly relevant question.

Several analyses have been performed regarding uncertainty of the calculated flood values and their changes. From comparing own results with published values of the Thuringian Environment Agency (TLUG), results indicate that own values are generally lower than TLUG values, which holds true for all return periods, gauges and time periods (mean difference $-20 \%$, Fig. 5a). The reason can probably be found in the longer database of the TLUG values. As a second indicator of uncertainty, the standard deviation of all flood value results at one gauge for the different return periods is calculated with respect to the mean. In Fig. 5b it becomes clear that the standard deviation is similar in all time periods. This, together with the results from comparison with TLUG flood values, is interpreted as indicator of robustness of results. Moreover, the standard deviation is increasing with increasing return values. This supports the remark from above to consider flood values of return periods higher than 50 years only with great care. Also, in Fig. 5c, the change of standard deviation from the mean, using all distributions and only those with "ok" fit is presented. It becomes clear that from the reduction of distributions, an enhancement is achieved for all considered return periods: the standard deviation is reduced, which points to more homogenous results from the considered distributions.

\section{Summary and conclusion}

From analyzing measured runoff time series of different catchments in Thuringia, Germany, representing the spatially heterogeneous landscape and climate conditions in the wet and cold midrange mountains and the dry Thuringian basin, changes in flow characteristics are detected. Analyses include Mann-Kendall trend tests of daily time series of 19 gauges, representing 48 years mean length in the time periods between 1922 and 2005. Runoff indicators for mean flow, high flow and low flow show significantly increasing trends, especially in the mountainous area, in winter and throughout the year. In this region, trend analyses of measured climate variables have shown that precipitation increases in winter. Flow indicators in summer show significantly decreasing trends throughout the study area. In summer, long term climate variable time series indicate temperature increase and precipitation decrease for Thuringia. Results of the trend analyses hint to climate induced significant changes in Thuringian runoff characteristics in the past 70 years. The robustness of the results can be tested in more detailed further analyses using different methods, e.g. trend tests in splitted time series. This was not within the scope of the presented analyses here.

Changes in flood values at different return periods were assessed at 8 gauges within the time period 1949-1999. Flood quantiles were derived from extreme values analyses by fitting 8 theoretical distributions with the method of L-moments, assessing goodness-of-fit and calculating mean flood quantiles from the distribution results. From comparing flood values from 2 time periods (1949-1979 and 


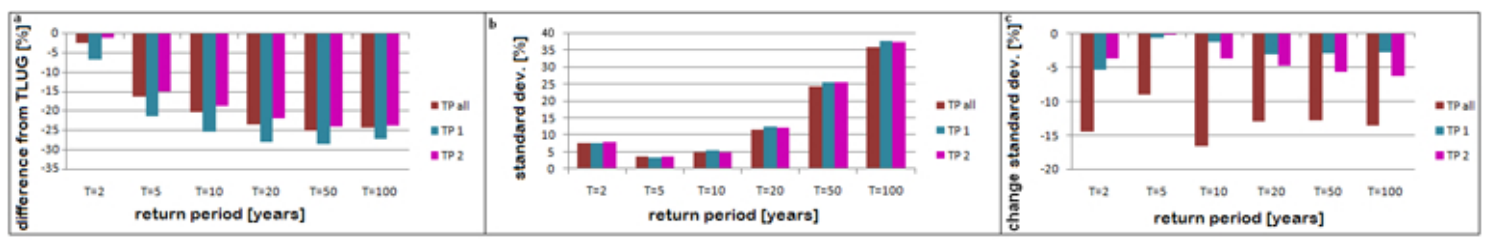

Fig. 5. (a-c) Results of uncertainty analyses; a: comparing own results in 6 annual flood return periods (means of 8 gauges, distributions with "ok" fit) with TLUG values in 3 time periods; (b) mean standard deviations of 6 annual flood return values (means of 8 gauges, distributions with "ok" fit) from mean in 3 time periods; (c) change in standard deviation of 6 annual flood return values (means of 8 gauges) when using only "well" fitted distribution in 3 time periods.

1969-1999) with the reference flood values of the whole time period, changes can be detected. Results indicate that flood values in Thuringia have increased in the later time period regarding the whole year $(+5 \%)$ and the winter $(+15 \%)$ but have decreased in summer $(-3 \%)$. This holds true for all regarded return periods $(2,5,10,20,50,100$ years) and most gauges.

In sum, results of the statistical tests of measured runoff time series in Thuringia indicate that high runoff has an increasing tendency, especially during winter flood periods. Flood values of annual maximum flow, which statistically return every $2,5,10,20,50$ or 100 years, seem to be getting higher within this season as well. Dimensioning in water engineering might have to take such tendencies into account. Low flow conditions seem to be getting more severe in Thuringia, with less runoff at the gauges for the analyzed low flow indicator in summer.

Further studies should regard results of regional climate projections with respect to their impact on runoff characteristics and water regime.

Edited by: R. Ludwig, K. Schulz, and M. Disse

Reviewed by: two anonymous referees

\section{References}

Bartels, H., Dietzler, B., Malitz, G., Albrecht, F. M., and Guttenberger, J: KOSTRA-DWD-2000, Starkniederschlagshöhen für Deutschland (1951-2000), Fortschreibungsbericht, Offenbach am Main, 2005.

Bates, B. C., Kundzewicz, Z. W., and Palutikof, J. P. (Eds.): Climate Change and Water, IPCC Technical Paper VI, IPCC Secreteriat, Geneva, 2008.

Bernhofer, C., Goldberg, V., and Franke, J.: REKLI - Aufbau einer Klimadatenbank und Regionale Klimadiagnose für Thüringen, Abschlussbericht zum Forschungsvorhaben der Thüringer Landesanstalt für Umwelt und Geologie, Dresden, 2003.

Bernhofer, C., V. Goldberg, and Franke, J.: REKLI II. Optimierung der Klimadatenbank REKLI für Auswertungen im Bereich Wasserwirtschaft, Abschlussbericht, Institut für Hydrologie und Meteorologie, Technische Universität Dresden, Dresden, 2005.

Coles, S.: An Introduction to Statistical Modeling of Extreme Values, Springer, Berlin, Germany, 2001.
Deutscher Verband für Wasserwirtschaft und Kulturbau e.V. (DVWK): Statistische Analyse von Hochwasserabflüssen, Verlag und Vertrieb Wirtschafts- und Verlagsgesellschaft Gas und Wasser mbH, Bonn, 1999.

Fowler, H. J., Blenkinsop, S., and Tebaldi, C.: Review - Linking climate change modelling techniques for hydrological modelling, Int. J. Climatol., 27, 1547-1578, 2007.

Helsel, D. R. and Frans, L. M.: Regional Kendall Test for Trend, Environ. Sci. Technol., 40, 4066-4073, 2006.

Klein-Tank, A. M. G., Zwiers, F. W., and Zhang, X.: Guidelines on Analysis of extremes in a changing climate in support of informed decisions for adaptation, Geneva, 2009.

KLIWA: Langzeitverhalten der Hochwasserabflüsse in BadenWürttemberg und Bayern, KLIWA Heft 2, Karlsruhe, 2002.

KLIWA: Langzeitverhalten der mittleren Abflüsse in BadenWürttemberg und Bayern, KLIWA Heft 3, Karlsruhe, 2003.

KLIWA: Regionale Klimaszenarien für Süddeutschland. Abschätzung der Auswirkungen auf den Wasserhaushalt, KLIWA Heft 9, Mannheim, 2006.

KLIWA: Monitoringbericht 2008, Karlsruhe, Hof, Mainz, 2008.

Kundzewicz, Z. W. and Robson, A. J.: Change detection in hydrological records - a review of the methodology, Hydrolog. Sci. J., 49, 7-19, 2004.

Kundzewicz, Z. W., Graczyk, D., Maurer, T., Pinskwar, I., Radziejewski, M., Svensson, C., and Szwed, M.: Trend detection in river flow series: 1 . Annual maximum flow, Hydrolog. Sci. J., 50, 797-810, 2005.

Lindström, G. and Bergström, S.: Runoff trends in Sweden 18072002, Hydrolog. Sci. J., 49, 69-83, 2004.

Maraun, D., Wetterhall, F., Ireson, A. M., Chandler, R. E., Kendon, E. J., Widmann, M., Brienen, S., Rust, H. W., Sauter, T., Themeß1, M., Venema, V. K. C., Chun, K. P., Goodess, C. M., Jones, R. G., Onof, C., Vrac, M., and Thiele-Eich, I.: Precipitation downscaling under climate change: recent developments to bridge the gap between dynamical models and the end user, Rev. Geophys., 48, RG3003, doi:10.1029/2009RG000314, 2010.

Mudelsee, M., Deutsch, M., Börngen, M., and Tetzlaff, G.: Trends in flood risk of the River Werra (Germany) over the past 500 years, Hydrolog. Sci. J., 51, 818-833, 2006.

Parry, M. L., Canziani, O. F., Palutikof, J. P., and Co-authors: Technical Summary. Climate Change 2007: Impacts, Adaptation and Vulnerability, Contribution of Working Group II to the Fourth Assessment Report of the Intergovernmental Panel on Climate Change, edited by: Parry, M. L., Canziani, O. F., Palutikof, J. P., van der Linden, P. J., and Hanson, C. E., Cambridge University Press, Cambridge, UK, 23-78, 2007. 
Prellberg, D.: Langjährige Hochwasserabflüsse in Rheinland-Pfalz, in: KLIWA: 4. KLIWA-Symposium am 3. und 4. Dezember 2009 in Mainz, Fachvorträge, Klimaveränderung und Konsequenzen für die Wasserwirtschaft, KLIWA-Heft 15, Karlsruhe, Hof, Mainz, 2010.

Petrow, T. and Merz, B: Trends in flood magnitude, frequency and seasonality in Germany in the period 1951-2002, J. Hydrol., 371, 129-141, 2009.

Robson, A. J.: Evidence for trends in UK flooding, Philos. T. R. Soc. A, 360, 1327-1343, 2002.

Svensson, C., Kundzewicz, Z. W., and Maurer, T.: Trend detection in river flow series: 2 . Flood and low-flow index series, Hydrolog. Sci. J., 50 (5), 811 - 824, 2005.
Stahl, K., Hisdal, H., Hannaford, J., Tallaksen, L. M., van Lanen, H. A. J., Sauquet, E., Demuth, S., Fendekova, M., and Jódar, J.: Streamflow trends in Europe: evidence from a dataset of nearnatural catchments, Hydrol. Earth Syst. Sci., 14, 2367-2382, doi:10.5194/hess-14-2367-2010, 2010.

Yue, S., Pilon, P., Phinney, B., and Cavadias, G.: The influence of autocorrelation on the ability to detect trend in hydrological series, Hydrol. Process., 16, 1807-1829, 2002.

Zolina, O., Simeer, C., Kapala, A., Bachner, S., Gulev, S., and Maechel, H.: Seasonally dependent changes of precipitation extremes over Germany since 1950 from a very dense observational network, J. Geophys. Res. Lett., 113, D06110, doi:10.1029/2007JD008393, 2008. 